\title{
E्己̌rekão \\ Formação de Professores e Didática para Desenvolvimento Humano
}

\author{
José Carlos Libâneo' \\ 'Pontifícia Universidade Católica de Goiás (PUC-GO), Goiânia/GO - Brasil
}

RESUMO - Formação de Professores e Didática para Desenvolvimento Humano. $\mathrm{O}$ artigo discute o problema da dissociação e do paralelismo entre dois tipos de conhecimento na formação profissional de professores, o disciplinar e o pedagógico. São apresentadas posições teóricas sobre esta questão para, em seguida, dar destaque à teoria do ensino para o desenvolvimento humano de Davydov como alternativa ao enfrentamento do problema. Por fim, argumenta sobre o potencial dessa teoria para a compreensão da necessária conexão entre didática, didáticas específicas e metodologias de ensino de modo a assegurar, no currículo, a interpenetração entre o conhecimento disciplinar e o conhecimento pedagógico.

Palavras-chave: Formação de Professores. Didática Desenvolvimental. Conhecimento Disciplinar. Conhecimento Pedagógico. Ensino e Desenvolvimento Humano.

ABSTRACT - Teachers Education and the Didactics for Human Development. The paper discusses the problem of decoupling and parallelism between two types of knowledge in the teacher education, the disciplinary knowledge and the pedagogical knowledge. Theoretical positions on this issue are presented, and next Davydov's teaching theory to human development is emphasized as an alternative to face the problem. Finally, it argues for its potential to understand the necessary link between didactics, specific didactics, and teaching methodologies to assure, in the curriculum, the interweaving of disciplinary knowledge and pedagogical knowledge. Keywords: Teaching Education. Developmental Didactics. Disciplinary Knowledge. Pedagogical Knowledge. Teaching and Human Development. 
Formação de Professores e Didática para Desenvolvimento Humano

\section{Introdução}

Nas três últimas décadas ganharam destaque no Brasil estudos sobre a formação de professores acompanhando a tendência mundial de investigações em torno desse tema, originados em boa parte de organismos internacionais como a OCDE, UNESCO e o Banco Mundial, chegando a constituir o maior número de ensaios e pesquisas no campo da educação (Nóvoa, 1992; Nóvoa, 2009; Perrenoud, 1993; Pimenta, 2002; Contreras, 2012; Sacristán, 2002; Gatti; Barretto; André, 2011; Gatti, 2012, entre outros).

Tais investigações estiveram ligadas, de algum modo, a reformas educativas implementadas em vários países europeus e latino-americanos, articuladas com programas de desenvolvimento econômico e social. Várias concepções de formação se difundiram no meio educacional como as do professor investigador, do professor reflexivo, do professor intelectual crítico, influenciando políticas e programas em todo o mundo. Presentemente, vários aspectos dessa formação continuam sendo objeto de pesquisas como as políticas curriculares, a formação inicial e continuada, os saberes docentes, as questões salariais e condições de trabalho, a preparação de professores para modalidades específicas de ensino, as características da identidade profissional, etc.

Neste texto, analisa-se a dissociação entre o conhecimento disciplinar e o conhecimento pedagógico ${ }^{1}$, considerada aqui como um dos problemas mais persistentes na organização dos currículos para a formação profissional de professores. A discussão desse problema no âmbito da formação profissional é feita com base em pesquisas que investigaram concepções de formação e matrizes curriculares em relação à licenciatura em pedagogia e às licenciaturas em conteúdos específicos, bem como em estudos sobre saberes docentes. Explicitado o problema, sugere-se a teoria do ensino para o desenvolvimento humano de Davydov $^{2}$ para elucidar as relações e propor formas de integração entre o conhecimento disciplinar e o conhecimento didático.

Pesquisas recentes (Gatti; Nunes, 2009; Libâneo, 2010a; Libâneo, 2010b; Libâneo, 2013) buscaram esclarecer um dos nós da formação profissional de professores: as dificuldades dos professores em incorporar e articular em seu exercício profissional dois requisitos dessa profissão: o domínio dos conteúdos da disciplina e o domínio de saberes e habilidades para ensinar esses conteúdos. Desse modo, confirmam a persistência da dissociação entre os conhecimentos disciplinar e pedagógico nos cursos de formação de professores, ao mesmo tempo em que evidenciam que tal dissociação aparece com características muito diferentes quando se trata da licenciatura em pedagogia e das licenciaturas em conteúdos específicos. Na primeira, em que se forma o professor polivalente para a etapa inicial da Educação Básica, é frequente a predominância do aspecto metodológico das disciplinas sobre os conteúdos. Nesse caso, o sentido de pedagógico se limita a um conhecimento teóri-

630 Educação \& Realidade, Porto Alegre, v. 40, n. 2, p. 629-650, abr./jun. 2015. 
co genérico e o conhecimento disciplinar se restringe à metodologia do ensino das disciplinas, no entanto, desvinculada do conteúdo que lhes dá origem, pois, como mostram as pesquisas mencionadas, aos futuros professores não são ensinados os conteúdos do currículo do ensino fundamental. Nas demais licenciaturas, em que se forma o professor especialista em conteúdos de certa área científica, há visível ênfase nesses conteúdos e pouca atenção à formação pedagógica, quase sempre separada da formação disciplinar. Nos dois formatos curriculares verifica-se a dissociação entre aspectos inseparáveis na formação de professores: o conhecimento do conteúdo (conhecimento disciplinar) e o conhecimento pedagógico do conteúdo (conhecimento pedagógico-didático). As ênfases são, portanto, invertidas: na licenciatura em pedagogia há supervalorização do conhecimento pedagógico geralmente não articulado aos conteúdos e resultando numa formação demasiadamente genérica; nas demais licenciaturas prevalece o conhecimento disciplinar, de caráter transmissivo e quase sempre não vinculado à pedagogia, quando muito adotando uma didática meramente instrumental.

O que ocorre nas concepções formativas e nos currículos, com consequência na conduta profissional dos professores, é a crença de que uma coisa é o conhecimento disciplinar com sua lógica, sua estrutura e seus modos próprios de investigação e outra coisa é o conhecimento pedagógico, entendido como domínio de procedimentos e recursos de ensino sem vínculo com o conteúdo e os métodos de investigação da disciplina ensinada.

Estas constatações se refletem na falta de articulação entre as disciplinas didática e didáticas específicas, estas últimas frequentemente reduzidas a metodologias de ensino de (Língua Portuguesa, Ciências, Matemática, etc.). As duas disciplinas compõem os currículos de formação de professores, mas enquanto os professores das didáticas específicas tendem a considerar dispensável uma didática geral, os de didática fazem reparos ao pouco interesse de seus colegas pelos saberes pedagógicos como as teorias da educação, a psicologia da aprendizagem, as teorias do ensino, e a própria didática. Os professores das didáticas específicas afirmam que os pedagogos não têm nada a fazer, pois sem conhecer os conteúdos específicos das matérias nada podem dizer sobre o ensino dessa matéria. Já os professores de didática dirão: não é possível alguém ensinar uma matéria desconhecendo as características individuais e sociais dos alunos e o contexto social e cultural em que vivem, os critérios de seleção e organização dos conteúdos, o papel do ensino na formação da personalidade, as condições mais adequadas de aprendizagem, a elaboração do plano de ensino, etc. Está claro que a busca da unidade e interdependência entre a didática e as didáticas disciplinares depende da compreensão das relações entre conhecimento disciplinar e conhecimento pedagógico, em que se realça na formação de professores a necessária ligação entre as dimensões pedagógica e epistemológica no ensino (Libâneo, 2008).

Educação \& Realidade, Porto Alegre, v. 40, n. 2, p. 629-650, abr./jun. 2015. 
Formação de Professores e Didática para Desenvolvimento Humano

As questões trazidas até aqui mostram, assim, conhecidos impasses que a legislação, as políticas e diretrizes curriculares e os movimentos organizados de educadores não têm conseguido levar a bom termo. Pergunta-se, pois: o que explica, após tantos anos de debates em torno da formação profissional de professores, a persistência da dissociação e do paralelismo entre conhecimentos disciplinares e conhecimentos pedagógicos? Por que professores de conhecimentos específicos continuam mantendo certa reserva sobre o trabalho de pedagogos? Como resolver na formação profissional, por um lado, a falta de domínio de conhecimentos específicos por parte dos pedagogos e, por outro, a falta de domínio de conhecimentos pedagógico-didáticos por parte dos professores de conhecimentos específicos? A insuficiente formação profissional dos professores não estaria ligada, na licenciatura em pedagogia, a um excesso de conhecimento pedagógico genérico desvinculado dos conteúdos específicos e, nas demais licenciaturas, a um certo conteudismo associado a deficiente formação pedagógica? O que explica que após tantas evidências do baixo desempenho de alunos do ensino fundamental em disciplinas como Língua Portuguesa e Matemática, os cursos de licenciatura em pedagogia continuem sem ensinar aos futuros professores os conteúdos que deverão ensinar às crianças? O que explica a persistência histórica dos antagonismos entre a didática geral e as didáticas específicas ou disciplinares? Finalmente, existem pistas para investigar como a epistemologia das ciências ensinadas pode penetrar no modo de trabalhar pedagogicamente/didaticamente os conteúdos, de forma que os conteúdos/métodos de uma ciência sejam os estruturantes do conhecimento pedagógico do conteúdo? É possível se pensar numa dupla determinação entre formação disciplinar e formação pedagógica?

Respostas a essas indagações requerem aportes de natureza política, sociológica, sociocultural, institucional, mas algumas delas podem ser buscadas nas formas de se conceber teoricamente a didática. As relações entre a formação profissional de professores e a didática são diretas e complementares. Embora alvo de críticas e até de menosprezo por setores do campo acadêmico em meio aos embates teóricos no campo das ciências humanas e da educação desde os anos 1980, a didática firma-se hoje como área de investigação consolidada, haja vista o expressivo número de publicações enfocando questões teóricas e epistemológicas como a natureza do processo de ensino-aprendizagem, a relação com a epistemologia das disciplinas, a articulação entre a didática e a pesquisa cultural, as aproximações interdisciplinares, os saberes docentes, e ainda questões do exercício docente como o ensino de disciplinas, a diversidade sociocultural, a relação com as tecnologias digitais, a relação teoria e prática na formação inicial e continuada (entre outros, Candau, 2003; Candau, 2011; Candau, 2012; Pimenta, 1997; Pimenta, 2002; Pimenta, 2010; Libâneo, 2008; Libâneo, 2010a; Libâneo, 2010b; Libâneo, 2011; Libâneo, 2012; Libâneo, 2014; Libâneo; Alves, 2012; Oliveira, 1992; Oliveira, 1997; Oliveira; Pacheco, 2013; Oliveira; André, 
2003; Veiga, 1999a; Veiga, 1999b; Veiga, 2010; Veiga, 2011; André, 1997; André, 2009; Masetto, 2000; Anastasiou; Alves, 2006; Franco, 2010; Franco, 2012). A solidez desse campo investigativo se evidencia, também, na realização, há mais de 30 anos, dos encontros de didática e práticas de ensino, a par da iniludível presença da disciplina praticamente em todos os cursos de licenciatura do país.

Para as intenções deste texto a didática é assumida como uma disciplina pedagógica indispensável ao exercício profissional, constituindo-se referência para a formação de professores à medida que investiga os marcos teóricos e conceituais que fundamentam, a partir das práticas reais de ensino-aprendizagem, os saberes profissionais a serem mobilizados na ação docente, de modo a articular na formação profissional a teoria e a prática. Na relação de continuidade entre estudos clássicos e contemporâneos em didática, tem sido consensual o entendimento de que seu objeto de estudo é o processo de ensino-aprendizagem ligado à apropriação de conhecimentos, em determinados contextos, visando à formação do aluno. Constitui-se, assim, como um sistema teórico de referência para dar suporte à análise de aspectos da formação profissional de professores no que se refere à relação entre conhecimento disciplinar e conhecimento pedagógico.

Faz-se, a seguir, uma breve reconstituição histórica da relação entre os dois tipos de conhecimento profissional buscando-se em seguida situá-los no âmbito dos estudos sobre saberes docentes. Finalmente, discute-se a teoria de ensino para o desenvolvimento humano de Davydov como um aporte à compreensão da necessária articulação entre conhecimento dos conteúdos da disciplina e conhecimento pedagógico da disciplina bem como da didática e das didáticas disciplinares.

\section{Uma Aproximação Histórica do Problema}

Um breve olhar histórico sobre o problema permite investigar a gênese da falta do conhecimento disciplinar no curso de licenciatura em pedagogia e a falta ou secundarização do conhecimento pedagógico nas licenciaturas de outras áreas de conhecimento. Damis (2002) mostra indícios da influência do modelo de formação de professores instituído na Universidade de São Paulo em 1938, o qual atribuía as responsabilidades de formação de professores a duas instâncias distintas: a dos conteúdos específicos aos Institutos de ensino básico; a dos estudos pedagógicos à Faculdade de Educação.

Diante dessas possibilidades ocorreu que, predominantemente nas universidades públicas e privadas, a formação de professores passou a ser função de duas unidades distintas: os institutos de ensino básico e as faculdades de educação. [...] A partir deste momento [...] a implantação dessa lei criou ainda a possibilidade para que a desvinculação entre o conteúdo específico e o conteúdo peda- 
Formação de Professores e Didática para Desenvolvimento Humano

gógico de formação do professor fosse mais acentuada (Damis, 2002, p. 111)

Trinta anos após, a Lei 5.540/68 (da Reforma Universitária) estabeleceu que a formação de professores e especialistas em educação em nível superior "[...] poderia continuar na Faculdade de Filosofia ou resultar de trabalhos distintos de institutos e faculdades”. Persistiu na legislação e, certamente nos currículos, a desvinculação entre o conteúdo específico e o conteúdo pedagógico na formação de professores. A situação foi agravada com a política de departamentalização imposta pela mesma lei: "na medida em que as disciplinas que compõem os conteúdos específicos e pedagógicos da docência foram distribuídas em vários departamentos, a questão da fragmentação na formação do professor ficou ainda mais intensificada" (Damis, 2002, p. 112). Para a autora, estaria aí a origem das dicotomias até hoje não superadas nas diretrizes para formação de professores: institutos de formação básica-faculdades de educação, bacharelado-licenciatura, universidade-institutos superiores de educação, licenciatura em pedagogia-licenciaturas em conteúdos específicos. Além disso, a despeito de vários instrumentos legais tentarem corrigir as distorções, é comum instituições formadoras de professores manterem o modelo implantado em 1939: curso de bacharelado em três anos para os conteúdos específicos e de licenciatura no último ano (chamado $3+1$ ), com o que se acentua a dissociação entre conteúdos específicos e formação pedagógica (Damis, 2002, p. 115-117).

Saviani, ao analisar o itinerário histórico da formação de professores, mostra que com a criação dos cursos normais (o primeiro em 1835), pratica-se um currículo em que os professores teriam que dominar os conteúdos a serem transmitidos às crianças, sem levar em conta o preparo didático, situação que vigorou até a criação dos Institutos de Educação a partir de 1932. Em 1939, foi criada a Faculdade Nacional de Filosofia da Universidade do Brasil de onde resultou a adoção para a formação de professores do "esquema $3+1$ ". O autor caracteriza bem a solução dualista que gerou esse modelo de formação:

Os cursos de licenciatura resultaram fortemente marcados pelos conteúdos culturais-cognitivos, relegando o aspecto pedagógico-didático a um apêndice de menor importância [...]. O curso de pedagogia, à semelhança do que ocorreu com os cursos normais, foi marcado por uma tensão entre os dois modelos. Embora seu objeto próprio estivesse todo ele embebido do caráter pedagógico-didático, este tendeu a ser interpretado como um conteúdo a ser transmitido aos alunos antes que como algo a ser assimilado teórica e praticamente para assegurar a qualidade da ação docente. Consequentemente, o aspecto pedagógico-didático, em lugar de se constituir em um novo modelo a impregnar todo o processo de formação docente, foi incorporado sob a égide do modelo dos conteúdos culturais-cognitivos (Saviani, 2009, p. 147). 
Saviani explicita dois modelos de formação: o modelo de conteúdos culturais-cognitivos, visando o domínio específico dos conteúdos da disciplina que o professor irá ensinar, e o modelo pedagógico-didático, visando o preparo pedagógico-didático (que acaba distorcido, quando essas disciplinas de preparo pedagógico-didático, como filosofia, sociologia, didática etc., se transformam em "conteúdos culturais-cognitivos”) (Saviani, 2009, p. 149). Esses modelos acabaram se mantendo ao longo dos anos, caracterizando as diferentes concepções formativas e formatos curriculares que ainda vigoram: a licenciatura em pedagogia manteve seu caráter generalista e ao mesmo tempo pedagógico-didático e as demais licenciaturas seu caráter "conteudista".

Recentemente, Gatti, Barretto e André (2011, p. 9), identificam as diferenças entre os dois percursos formativos quanto à concepção de formação e à organização curricular:

\begin{abstract}
A formação de professores para os anos iniciais da escolarização sempre foi separada da formação dos professores das disciplinas específicas e, por muitos anos, houve separação também em nível escolar: os primeiros eram formados em nível secundário (hoje, médio) e os segundos, em nível superior, em cursos isolados por área de conhecimento, nos chamados bacharelados. Essa condição deixou marcas de valor acadêmico e social que se refletem até nossos dias e tem implicações nas carreiras dos respectivos docentes.
\end{abstract}

Igualmente confirmam essa situação ao mencionar o efeito das diretrizes curriculares oficiais para a formação de professores nas licenciaturas de conteúdos específicos:

\begin{abstract}
Mesmo com ajustes parciais propostos nessas diretrizes, verifica-se nas licenciaturas de professores especialistas a prevalência da histórica ideia de oferecimento da formação com foco na área disciplinar específica, com pequeno espaço para a formação pedagógica. [...] mesmo com as orientações mais integradoras quanto à relação formação disciplinar-formação para a docência, na prática ainda se verifica a prevalência do modelo consagrado no início do século XX (Gatti; Barreto; André, 2011, p. 98).
\end{abstract}

Este breve recorrido histórico mostra que os impasses na formação de professores permanecem praticamente inalterados em termos de concepção formativa e formatos curriculares, sendo pouco afetada pelas mudanças legais, pelas políticas e diretrizes curriculares oficiais e pelas recomendações de movimentos de educadores.

Do breve histórico exposto, pode-se constatar que é real nos cursos de formação de professores a separação entre o conhecimento pedagógico e o conhecimento disciplinar, ainda que de modos diferentes quando se analisa a licenciatura em pedagogia e as licenciaturas em conteúdos específicos. O curso de licenciatura em pedagogia continua 
Formação de Professores e Didática para Desenvolvimento Humano

genérico e com uma débil formação nas metodologias, estando esta separada dos conteúdos específicos da educação infantil e séries iniciais do ensino fundamental, uma vez que estão ausentes do currículo. Por sua vez, nos cursos de licenciatura em conteúdos específicos ocorre a prevalência dos conteúdos das respectivas áreas de conhecimento em detrimento da formação pedagógica, com baixo número de horas na matriz curricular. No caso destes cursos, o problema não é a ênfase dada aos conteúdos específicos, mas a desarticulação entre a formação na área específica e a formação para a docência. O conhecimento pedagógico e o conhecimento disciplinar correm em paralelo, dissociados, aprofundando a desvinculação entre as metodologias de ensino e os conteúdos, entre métodos de ensino e métodos investigativos da ciência ensinada. Em síntese, a visão segmentada dessa relação leva à formação pouco sólida dos professores na especificidade disciplinar (no caso da licenciatura em pedagogia) e à formação pedagógica insuficiente e separada dos aspectos epistemológicos dos conteúdos (no caso das demais licenciaturas).

\section{Posições Teóricas Sobre Conhecimento Disciplinar e Conhecimento Pedagógico}

Na análise da formação de professores, a relação entre conhecimento disciplinar e conhecimento pedagógico vem sendo tratada, mundialmente, a partir de distintas posições sobre saberes docentes. Para o objetivo deste artigo importa destacar as contribuições dos canadenses Tardif e Gauthier (saberes da prática docente), da brasileira Pimenta (saberes docentes), dos franceses Develay, Meirieu e Chevallard (didáticas disciplinares), dos espanhóis Ariza e Toscano (saberes do professor em sua relação com as dimensões da sua prática) e do norte-americano Shulman (conceito de conhecimento pedagógico do conteúdo).

Para Tardif (2002), a prática dos docentes compõe-se de diferentes saberes, entre os quais são mantidas diferentes relações: saberes da formação profissional (ciências da educação e da ideologia pedagógica, ou seja, saberes pedagógicos); saberes disciplinares (correspondentes aos diversos campos do conhecimento); saberes curriculares (programas curriculares expressos em objetivos, conteúdos, métodos, ordenados pela instituição escolar); saberes experienciais (saberes específicos desenvolvidos pelos professores na prática de sua profissão).

Gauthier (1998, p. 24), concebendo o magistério como “[...] um oficio feito de saberes”, formula sua visão de saberes necessários ao professor para responder a exigências específicas de situações concretas de ensino e os identifica em cinco tipos: saberes disciplinares; saberes curriculares; saberes das ciências da educação; saberes da tradição pedagógica; saberes da ação pedagógica.

Pimenta (1997), em consonância com os autores citados, propõe três tipos de saberes articulados entre si: o saber da matéria, isto é, o co-

636 Educação \& Realidade, Porto Alegre, v. 40, n. 2, p. 629-650, abr./jun. 2015. 
nhecimento do professor sobre a disciplina que ensina; o saber pedagógico, que diz respeito ao conhecimento que resulta da reflexão confrontada entre o saber da matéria e os saberes da educação e da didática; o saber da experiência, construído a partir das experiências vivenciadas pelo professor e pelo aluno, incluindo suas representações sobre escola e ensino.

Os mencionados didatas franceses abordam questões sobre o ensino de conteúdos específicos, i.e., as didáticas disciplinares, tendo como referência duas dimensões: a natureza do saber a ensinar e a compreensão da relação com o saber dos alunos e do professor. Tal como expressa Develay (1993), a didática aborda as aprendizagens a partir da lógica dos saberes e a pedagogia aborda as aprendizagens a partir da lógica da classe. Enquanto a didática volta-se prioritariamente ao modo pelo qual os alunos se apropriam dos conhecimentos, a pedagogia volta-se à relação professor-alunos e às condições pelas quais se concretizam as ações didáticas. Esse autor mostra que o professor precisa dominar os conteúdos que ensina mas, especialmente, precisa desenvolver uma competência epistemológica para compreender a natureza do conhecimento, sua gênese e sua estrutura.

Meirieu (1998) critica a visão tradicional do ensino em que, primeiro, elege-se o conteúdo, em seguida o compreende e, no final, se fazem os exercícios, dentro de uma visão linear. Ele propõe uma concepção de ensino-aprendizagem em que os conhecimentos sejam integrados no projeto do sujeito que aprende, o qual formará suas próprias representações do objeto de conhecimento. Propõe, também, a formulação de objetivos voltados para operações mentais a realizar (dedução, indução, dialética, criatividade). Importa, assim, que o professor traduza os "conteúdos de aprendizagem" em "procedimentos de aprendizagem”, isto é, em uma sequência de operações mentais, pois, conforme escreve, nenhum conteúdo existe fora do ato que permite pensá-lo, da mesma forma que nenhuma operação mental funciona no vazio, isolada de um conteúdo (Meirieu, 1998, p. 119).

Chevallard (1991) põe a questão da relação entre o saber científico e o saber ensinado introduzindo o conceito de transposição didática que leva uma reorganização do saber visando sua compreensão pelo aluno. Ou seja, o trabalho que transforma um objeto de saber a ser ensinado em um objeto de ensino é denominado "transposição didática”, o que envolve a dimensão epistemológica do ensino.

Os espanhóis Ariza e Toscano (2001, p. 61) ao abordarem a relação entre conhecimento pedagógico e conhecimento disciplinar, advertem que embora "[...] muitos professores de nível secundário tendem a se ver mais como especialistas disciplinares do que como docentes [...], todos os professores desenvolvem inevitavelmente um conhecimento tácito relacionado aos processos de ensino-aprendizagem”. Para eles, professores que ensinam disciplinas científicas percebem-se muito mais como biólogos, físicos, matemáticos, etc. do que como professo-

Educação \& Realidade, Porto Alegre, v. 40, n. 2, p. 629-650, abr./jun. 2015. 
Formação de Professores e Didática para Desenvolvimento Humano

res, identificando seu conhecimento profissional com o conhecimento da disciplina de sua especialidade. Acabam incorporando dois tipos de saberes, o saber acadêmico e o saber-fazer tácito os quais, no entanto, “[...] possuem características epistemológicas claramente diferentes” (Ariza; Toscano, 2001, p. 61). O primeiro baseia-se na lógica científica da disciplina e, com frequência, está pouco relacionado a contextos históricos, sociológicos e metodológicos da produção científica; o segundo, ao contrário, é um conhecimento tácito, pouco reflexivo, baseado na lógica do pensamento cotidiano, pouco relacionado com os conceitos e teorias das ciências da educação (Ariza; Toscano, 2001, p. 62). Falta, portanto, aos professores o conhecimento pedagógico fundamentado, em razão do que recomendam aos professores especialistas em conteúdos específicos um conjunto de conhecimentos teórico-práticos de caráter integrador a partir de quatro dimensões: a dimensão científica (disciplina vista desde as perspectivas lógica, histórica, sociológica e epistemológica), dimensão psicopedagógica (questões de ensino e aprendizagem implicadas no ensino de uma disciplina), a dimensão empírica (saberes da experiência própria e dos demais professores), a dimensão integradora (didáticas específicas) integrando as três dimensões anteriores (Ariza; Toscano, 2001, p. 66).

Shulman (2005, p. 11) aponta sete tipos de conhecimentos necessários aos professores: conhecimento do conteúdo; conhecimento pedagógico geral, tendo em conta especialmente aqueles princípios e estratégias gerais de manejo e organização da classe que transcendem o âmbito da matéria; conhecimento do currículo, com um especial domínio dos materiais e os programas que servem como "ferramentas para o ofício" do docente; conhecimento pedagógico do conteúdo: especial amálgama entre matéria e pedagogia que constitui uma esfera exclusiva dos professores, sua própria forma especial de compreensão profissional; conhecimento dos alunos e de suas características; conhecimento dos contextos educativos, que abarcam desde o funcionamento do grupo ou da classe, a gestão e financiamento dos distritos escolares, até o caráter das comunidades e culturas; e conhecimento dos objetivos, as finalidades e os valores educativos. Para esse autor, o professor "[...] deve compreender as estruturas da matéria ensinada, os princípios de organização conceitual" e, ao mesmo tempo, ter o conhecimento pedagógico do conteúdo. Descreve o conceito de conhecimento pedagógico do conteúdo como aquele que "[...] representa a ligação entre a matéria e a didática, para compreender como determinados temas e problemas podem ser organizados, representados e adaptados aos diferentes interesses e habilidades dos alunos" (Shulman, 2005, p. 11). O autor ressalta, ainda, que o conhecimento pedagógico do conteúdo é o que distingue um excelente professor de outro que apenas sabe a sua disciplina. Este é um professor que sabe como transformar seu conhecimento da matéria em atividades e experiências que estimulam, envolvem e melhoram a aprendizagem ativa e a compreensão dos alunos (Shulman, 2005, p. 11).

638 Educação \& Realidade, Porto Alegre, v. 40, n. 2, p. 629-650, abr./jun. 2015. 
Os estudos mais clássicos mencionados, de alguma forma incluem no rol de saberes profissionais o conhecimento do conteúdo e o conhecimento pedagógico mas não são explicitadas formas de articulação entre eles, permanecendo como paralelos. Já os didatas franceses realçam as articulações necessárias entre didática e epistemologia das disciplinas, superando a separação entre o conhecimento disciplinar e o conhecimento pedagógico, trazendo elementos ricos para a compreensão do que significa “conhecimento pedagógico do conteúdo" em articulação com o conteúdo. É expressiva a afirmação de Cornu e Vergnioux (1992, p. 124) de que o método didático supõe o método próprio das disciplinas ensinadas, no sentido de que "[...] o primeiro não deve ser acrescentado nem substituído pelo segundo, mas buscar os objetos elementares e as formas de aplicação do segundo para tornar-se acessível: ele é a imaginação do segundo". A abordagem de Shulman traz substantivas contribuições para o conhecimento profissional do professor, no entanto, ainda que ajude a compreender a imbricação entre o conhecimento disciplinar e o conhecimento pedagógico, em sua teoria eles tendem, também, a se manter paralelos.

Desse modo, cabe perguntar: Como integrar na formação profissional os dois tipos de conhecimento que estão dissociados e correndo em paralelo? Como articular o conhecimento pedagógico do conteúdo ao conhecimento dos conteúdos/processos investigativos da ciência ensinada? Como professores podem aprender a introduzir transformações nos objetos de conhecimento de modo a suscitar motivos dos estudantes para a atividade de estudo?

Presume-se que a vinculação mais estreita da didática aos conteúdos específicos e a uma compreensão mais clara do seu papel na orientação do processo cognitivo do aluno poderia trazer maior credibilidade ao trabalho dos pedagogos no seu papel de orientar os processos de ensino-aprendizagem dos conteúdos específicos. Essa é a posição defendida a seguir, fundamentada no aporte da teoria de ensino de Davydov.

\section{A Teoria do Ensino para o Desenvolvimento e a Integração Entre Didática e Epistemologia das Disciplinas}

A teoria do ensino para o desenvolvimento possibilita uma compreensão das relações entre conhecimento disciplinar e conhecimento pedagógico diferente das concepções anteriormente descritas. Ela tem como pressuposto que a função preponderante da escola é a de assegurar os meios para os alunos se apropriarem dos conhecimentos e, assim, formarem um método teórico-conceitual de pensar e atuar. Esse método consiste da interiorização de operações mentais e se forma por meio de conceitos adequados em relação aos objetos de estudo que, enquanto modos de operação mental, são formados com base nos processos lógicos e investigativos das ciências. O processo de apropriação dos conhecimentos na forma de conceitos requer dos alunos mudanças no 
Formação de Professores e Didática para Desenvolvimento Humano

desenvolvimento psíquico, propiciando-lhes novas capacidades intelectuais para apropriação de conhecimentos de nível mais complexo. Nessa concepção, o conhecimento pedagógico do professor é condição necessária para ajudar o aluno a mobilizar suas capacidades intelectuais para a apropriação dos conceitos. O professor deve não só dominar o conteúdo mas, especialmente, os métodos e procedimentos investigativos da ciência ensinada. Portanto, o conhecimento disciplinar e o conhecimento pedagógico estão mutuamente integrados.

Os pressupostos teoria do ensino desenvolvimental formulados pelo psicólogo e pedagogo russo Vasili V. Davydov (1988) baseiam-se na tradição da teoria histórico-cultural iniciada com Lev S. Vygotsky. Nela, a educação escolar consiste em um processo de promover aos alunos a apropriação da cultura e da ciência desenvolvidas social e historicamente, como signos culturais, "instrumentos psicológicos" que os ajudam a organizar seu comportamento e suas ações, através do processo de interiorização da cultura (Vygotsky, 1984). Esta apropriação é condição para seu desenvolvimento cognitivo, afetivo e moral dos alunos. Para isso, a escola cumpre sua função social quando promove e amplia o desenvolvimento dos processos psíquicos dos alunos por meio dos conteúdos atuando, desse modo, na formação da sua personalidade. Segundo Vygotsky, o aprendizado não é, em si mesmo, desenvolvimento mas, se organizado corretamente, ativa processos de desenvolvimento mental da criança. Para ele boa instrução, compreendida como unidade de ensino-aprendizagem ${ }^{3}$, é a que se antecipa e mantém o foco na próxima etapa do desenvolvimento, ao despertar e provocar "[...] toda uma série de funções que se encontram em estado de maturação na zona de desenvolvimento próximo" (Vygotsky, 2007, p. 360), guiando o processo de desenvolvimento.

Davydov ampliou as ideias precursoras de Vygotsky afirmando que a educação e o ensino atuam no desenvolvimento por meio do processo da apropriação do conhecimento teórico-científico que, por sua vez, possibilita o desenvolvimento das capacidades e habilidades correspondentes aos procedimentos lógicos e investigativos de constituição de uma área de conhecimentos. Nesse processo, o desenvolvimento humano integral do aluno se efetiva por meio da atividade de estudo, cujo conteúdo são os objetos científicos (os conteúdos) a serem apropriados pelos alunos e reconstituídos sob a forma teórico-conceitual, base para a formação de operações mentais. A reconstituição e reestruturação do objeto de estudo constituem o processo de internalização pelo qual os alunos modificam a estrutura de sua própria atividade cognitiva, resultando em desenvolvimento. Nesse sentido, “[...] a apropriação é o resultado da atividade empreendida pelo indivíduo quando ele aprende a dominar métodos socialmente desenvolvidos de lidar com o mundo dos objetos e a transformar esse mundo, os quais gradualmente tornam-se o meio da própria atividade do indivíduo" (Davydov; Markova, 1987, p. 5).

640 Educação \& Realidade, Porto Alegre, v. 40, n. 2, p. 629-650, abr./jun. 2015. 
Para Davydov, os conceitos são procedimentos lógicos do pensamento, isto é, modos gerais de acesso ao objeto de conhecimento os quais vão se formando no processo de ensino-aprendizagem com base nos processos investigativos e procedimentos lógicos próprios de uma ciência. Segundo ele, "[...] o conceito constitui o procedimento e o meio da reprodução mental de qualquer objeto como sistema integral; ter um conceito sobre esse objeto significa dominar o procedimento geral de construção mental deste objeto" (Davydov, 1988, p. 153). Tal procedimento geral deve ser buscado na história da ciência ensinada, pois o processo mental a ser formado pelos alunos no estudo de uma ciência tem a ver com a forma de constituição dos objetos dessa ciência. Desse modo, para compreender um conceito é preciso reconstituir seu surgimento no percurso histórico da ciência. Para isso, o caminho didático para a formação dos conceitos pelos alunos deve reproduzir ou recriar o caminho investigativo já percorrido pelo pensamento científico, de modo que os alunos interiorizem métodos e estratégias cognitivas para desenvolver seu próprio pensamento. Segundo Davydov:

\begin{abstract}
O sujeito individual, por meio da apropriação, reproduz em si mesmo as formas histórico-sociais da atividade. [...] Graças ao processo de interiorização, a realização desta atividade se converte em individual e os meios de sua organização, em meios internos (Davydov, 1988, p. 11). [...] As crianças em idade escolar não criam conceitos, imagens, valores e normas da moral social, mas as assimilam no processo da atividade de estudo. Mas, ao realizar esta atividade, elas realizam ações mentais semelhantes àquelas pelas quais estes produtos da cultura espiritual foram elaborados historicamente. Em sua atividade de estudo, as crianças reproduzem o processo real pelo qual os indivíduos criam conceitos, imagens, valores e normas. Por isso, o ensino de todas as matérias na escola deve ser estruturado de modo que, de forma condensada e abreviada, reproduza o processo histórico real da geração e desenvolvimento do conhecimento (Davydov, 1988, p. 174).
\end{abstract}

Com base nesse aporte teórico, cabe à didática investigar os processos de ensino-aprendizagem na sua relação com conteúdos específicos. Assim, o núcleo do problema didático é o conhecimento enquanto processo mental a ser desenvolvido pelo aluno para conhecer os objetos, ou seja, seu processo de formação de conceitos. Trata-se, pois, de uma didática cuja especificidade epistemológica é o estudo da atividade de ensino-aprendizagem na relação com saberes, em situações pedagógicas contextualizadas, visando ao desenvolvimento do aluno. Nessa concepção, é fundamental a unidade entre o aprender e o ensinar, em que o professor atua na direção da atividade autônoma dos alunos para se apropriem dos produtos da cultura, da ciência, da arte, constituídos ao longo da experiência humana. Este processo é designado mediação didática, isto é, mediação das relações do aluno com os objetos de conhecimento (processo de ensino-aprendizagem), em contextos sociais 
Formação de Professores e Didática para Desenvolvimento Humano

e culturais concretos, em que se articulam o ensino, a aprendizagem e o desenvolvimento dos alunos. Para isso, a didática articula a lógica da organização dos saberes a ensinar (dimensão epistemológica), a lógica dos modos de aprender (dimensão psicopedagógica), e a lógica da atuação no ensino das práticas socioculturais.

Essas considerações permitem evidenciar a relação de dependência da didática com a epistemologia das disciplinas, do que decorre que os professores precisam não só ter domínio dos resultados da ciência como, também, dos procedimentos lógicos e investigativos dessa ciência, pois é daí que se originam as capacidades intelectuais a formar nos alunos na atividade de estudo. Nesse caso, o conhecimento pedagógico do conteúdo consiste em ajudar o aluno a transformar os conteúdos em objetos do pensamento, ou seja, em conceitos teóricos. Reside aí, precisamente, a problemática da relação entre o conhecimento disciplinar (conhecimento do conteúdo) e o conhecimento pedagógico na formação de professores, abordada a seguir.

\section{A Integração Entre o Conhecimento Disciplinar e o Conhecimento Pedagógico na Formação de Professores}

Com base nas considerações anteriores, é possível identificar os pontos cardeais de uma didática para o desenvolvimento dos alunos. Se a atividade de ensino-aprendizagem (instrução) é a que promove e amplia o desenvolvimento das capacidades intelectuais dos alunos, trata-se de buscar tais capacidades nos procedimentos lógicos e investigativos que deram origem ao conhecimento científico do qual deriva a matéria ensinada. Isto é assim porque as operações mentais que levam aos conceitos teóricos de um objeto de estudo são equivalentes aos processos de investigação e de constituição da matéria, dos seus conceitos, no desenvolvimento histórico de cada ciência. A culminância da aprendizagem é a consolidação do método de pensar por conceitos teóricos das ciências, o que é possibilitado aos alunos por um ensino que leve ao processo de interiorização desses conceitos como meios da sua atividade interna para lidar com a realidade.

O conhecimento teórico na tradição histórico-cultural, baseada no materialismo histórico e dialético, não tem o sentido de conhecimento especulativo desconectado da realidade. Trata-se de um conhecimento que reúne e reflete o conjunto de procedimentos lógicos do pensamento pelos quais o sujeito realiza uma reflexão sobre as características e propriedades de um objeto e que constituem, ao mesmo tempo, as operações mentais (próprias do sujeito pensante) que permitem a reconstrução mental deste objeto. Pensar teoricamente é, então, desenvolver processos mentais pelos quais se chega aos conceitos, estes convertidos em instrumentos mentais para se fazer generalizações conceituais e aplicá-los a problemas específicos. Tal como escreve Chaiklin: 
O conceito significa um conjunto de procedimentos para deduzir relações particulares de uma relação abstrata. [...] A estratégia educacional básica para dar aos alunos a possibilidade para reproduzir pensamento teórico é criar tarefas instrucionais cujas soluções requeiram a formação de abstrações substantivas e generalizações sobre as ideias centrais do assunto. Esta aproximação é fundamentada na ideia de Vygotsky de interiorização, ou seja, aprende-se o conteúdo da matéria aprendendo os procedimentos pelos quais se trabalha na matéria de estudo (Chaiklin, 1999, p. 191).

Na teoria de Davydov os conteúdos de ensino são os conceitos científicos e métodos de transformação de objetos formados social e historicamente a serem apropriados pelos estudantes de modo a fazer parte de suas próprias estruturas mentais. O termo conteúdos deve ser entendido como o conjunto de conhecimentos científicos de uma disciplina, constituídos social e historicamente, enquanto produtos da experiência social e histórica humana. A atividade de ensino tem seu foco, portanto, no conhecimento, mas especialmente, no processo mental do conhecimento, ou seja, na formação e desenvolvimento das capacidades e habilidades intelectuais. Não se trata de conhecimentos já prontos, mas reconstituídos a partir das condições históricas e epistemológicas que os originaram e os tornaram essenciais. Desse modo, para aprender um conteúdo científico, importa mais o domínio do processo de sua origem e desenvolvimento na trajetória de sua constituição como objeto de conhecimento, do que o domínio apenas de seu conteúdo formal, isto é, do seu resultado. Nos processos de ensino-aprendizagem os estudantes, ao incorporarem o conhecimento e as habilidades relacionadas com a constituição desse conhecimento incorporam, também, as capacidades construídas historicamente para desenvolver a consciência e o pensamento teóricos.

Para Davydov, a aquisição de conceitos científicos e o desenvolvimento das capacidades cognitivas e operativas, compreendidos em sua relação mútua, são dois elementos indissociáveis do ensino-aprendizagem escolar. O que está em questão é como o ensino pode impulsionar o desenvolvimento das competências cognitivas mediante a formação de conceitos e o desenvolvimento do pensamento teórico, e por quais meios os alunos podem melhorar e potencializar sua aprendizagem. Trata-se de saber o que e como fazer para estimular as capacidades investigadoras dos alunos ajudando-os a desenvolver competências e habilidades mentais. Em razão disso, uma didática a serviço de uma pedagogia voltada para a formação de sujeitos pensantes e críticos deverá salientar em suas investigações as estratégias cognitivas gerais de cada ciência pelas quais os alunos aprendem a internalizar conceitos, competências e habilidades do pensar, modos de ação, que vão se convertendo em meios de sua própria atividade, a fim de analisar e resolver problemas em situações concretas da vida prática. Davydov explicita seu entendimento dessas questões: 
Formação de Professores e Didática para Desenvolvimento Humano

O saber contemporâneo pressupõe que o homem domine o processo de origem e desenvolvimento das coisas mediante o pensamento teórico, estudado e descrito pela lógica dialética. O pensamento teórico tem seus tipos específicos de generalização e abstração, seus procedimentos de formação dos conceitos e das operações com eles. Justamente, a formação de tais conceitos abre aos escolares o caminho para dominar os fundamentos da cultura teórica atual. O ensino escolar deve ser orientado para a comunicação desses conhecimentos, os quais podem ser assimilados no processo de generalização e abstração teóricas que conduzem aos conceitos teóricos. A escola, a nosso juízo, deve ensinar as crianças a pensar teoricamente (Davydov, 1988, p. 6).

Essas considerações mostram que conhecimento disciplinar (no qual se incluem métodos investigativos da ciência ensinada) e o conhecimento pedagógico (no qual se incluem os métodos de ensino) são inseparáveis, pois os procedimentos pedagógicos de formação dos processos mentais são derivados dos processos investigativos das ciências pelos quais se chega à constituição de um conteúdo. Com efeito, as bases do conhecimento pedagógico estão já presentes no conhecimento disciplinar e o conhecimento pedagógico do conteúdo está diretamente relacionado ao conhecimento do conteúdo.

\section{Derivações Metodológicas para o Processo de Ensino-Aprendizagem}

Na teoria do ensino para o desenvolvimento, a abordagem pedagógico-didática de um conteúdo pressupõe a abordagem epistemológica desse conteúdo. Desse modo, o primeiro princípio metodológico relacionado com o conhecimento pedagógico do conteúdo é que a formação de conceitos científicos pelos alunos resulta da apropriação dos modos de pensar, investigar e atuar da ciência ensinada, com o que os conceitos convertem-se em ferramentas mentais internalizadas para lidar com o mundo objetivo, com os outros e consigo mesmos.

As formulações de Davydov nos levam a afirmar que o modo de lidar pedagogicamente com uma disciplina depende do modo de lidar epistemologicamente com essa disciplina. Considerando que os métodos de ensino são derivados dos conteúdos, pode-se afirmar, por um lado, que os conteúdos e procedimentos lógico-investigativos de uma ciência são estruturantes do conhecimento pedagógico necessário para ensinar essa ciência; por outro, que os conhecimentos disciplinares requerem conhecimentos pedagógicos. Consequentemente, o conhecimento pedagógico do conteúdo pressupõe organizar o ensino dos conteúdos de forma a propiciar situações-problema em que os alunos possam reproduzir os procedimentos investigativos da ciência e, desse modo, formarem habilidades intelectuais análogas àqueles procedimentos. Essa teoria provê, portanto, um fundamento explicativo mais avançado da relação indissolúvel entre o plano epistemológico (da ciência ensina- 
da) e o plano pedagógico-didático (do ensino dessa ciência), quer dizer, entre o conhecimento disciplinar e o conhecimento pedagógico.

\section{Derivações para a Formação de Professores}

Ao longo deste texto perpassou a ideia de que a escola é um lugar de formação cultural e científica dos alunos em articulação com a diversidade social e cultural, por um processo ensino-aprendizagem centrado na formação de processos psíquicos visando o desenvolvimento cognitivo, afetivo e moral dos estudantes, e é nessa condição que se transforma em instância de democratização e promoção da inclusão social. Para tanto, são necessários professores com conhecimento dos conceitos que ensinam e conhecimento pedagógico para ajudar os alunos a pensar e atuar com esses conceitos.

Na perspectiva teórica sugerida aqui, as práticas de formação de professores implicam a interpenetração da formação disciplinar e da formação pedagógica, envolvendo tanto os professores das disciplinas de conteúdos quanto das disciplinas pedagógicas. Trata-se de considerar, na concepção formativa, no formato curricular e nas práticas de ensino, a perspectiva epistemológica e a perspectiva metodológica, articulando na formação do professor a epistemologia da disciplina científica com a didática dessa disciplina, bem como a interconexão entre do conteúdo e com as ações mentais que lhes correspondem. Conforme escreve Meirieu (1998, p. 119), “[...] nenhum conteúdo existe fora do ato que permite pensá-lo, da mesma forma que nenhuma operação mental pode funcionar no vazio". Para isso, o professor necessita ter uma concepção epistemológica da ciência que ensina, dos métodos lógicos e investigativos dessa ciência e das condições históricas e sociais do contexto de produção e aplicação dos conteúdos dessa ciência.

Tal constatação atinge diretamente as concepções de formação e os formatos curriculares dos atuais cursos de formação de professores. Com efeito, a dissociação e a visão segmentada entre conhecimento disciplinar e conhecimento pedagógico podem explicar uma formação pouco sólida na especificidade disciplinar (caso do curso de pedagogia) ou uma formação pedagógica insuficiente em relação a requerimentos de um processo de ensino-aprendizagem voltado para o desenvolvimento dos processos psíquicos dos alunos (caso das demais licenciaturas). Falta aos planejadores desses cursos o entendimento de que a epistemologia das ciências ensinadas deve penetrar no âmago do trabalho pedagógico com essas ciências, ou seja, os conteúdos específicos e os procedimentos investigativos da ciência que dão origem a esses conteúdos devem ser estruturantes do conhecimento pedagógico do conteúdo, junto com os aspectos psicopedagógicos e socioculturais. Por um lado, o pedagógico existe para o disciplinar, por outro, o ensino da disciplina requer o pedagógico. Sem esta dupla determinação, será inviável qualquer tentativa de aliar ensino dos conteúdos e formação 
Formação de Professores e Didática para Desenvolvimento Humano

pedagógica, conhecimento do conteúdo e conhecimento pedagógico do conteúdo.

Ganham importância nesse raciocínio a busca pela intersecção entre a didática e as didáticas específicas pois o objeto de estudo de ambas é o processo de ensino-aprendizagem. Ambas visam compreender a mediação didática dos conteúdos com foco na aprendizagem, na promoção e ampliação do desenvolvimento das capacidades intelectuais dos alunos e da sua personalidade. A questão-chave da didática está em que a ela cabe a organização pedagógico-didática dos conteúdos em associação com sua análise epistemológica, ou seja, a análise do objeto da ciência ensinada, seus métodos de investigação e os resultados da investigação, junto com a análise psicopedagógica das condições de ensino-aprendizagem. Desse modo, a didática enquanto ciência profissional do professor está referida a, pelo menos, quatro questões: a) a análise e seleção dos conteúdos que contribuem para a formação das capacidades cognitivas dos estudantes (conhecimento do conhecimento disciplinar); b) a identificação de operações mentais (capacidades intelectuais) mais relevantes para o desenvolvimento cognitivo, afetivo e moral dos alunos; c) as formas de organizar o conhecimento para trabalhar com os estudantes nas aulas e os meios pelos quais este conhecimento pode ser melhor e mais adequadamente internalizado (conhecimento pedagógico do conteúdo); d) a organização das situações pedagógico-didáticas. É a partir daí que ela, enquanto teoria do ensino e aprendizagem, generaliza princípios e procedimentos obtidos a partir das ciências da educação - psicologia do desenvolvimento e da aprendizagem, sociologia da educação, entre outras - e das pesquisas resultantes das próprias disciplinas específicas, pondo-os a serviço do processo de ensino e aprendizagem das disciplinas. Oferece às disciplinas específicas o que é básico, essencial e comum ao ensino, mas em íntima conexão com a lógica científica das disciplinas. Por sua vez, as didáticas específicas (ou disciplinares), com base nos saberes específicos com sua estrutura conceitual e procedimentos investigativos e nos saberes pedagógico-didáticos sobre ensino e aprendizagem, atuam nos aspectos epistemológicos do processo geral do conhecimento, nas peculiaridades epistemológicas de cada disciplina e nos processos externos e internos do desenvolvimento humano e da aprendizagem. Em síntese, as didáticas específicas têm como objeto de estudo as peculiaridades dos processos de ensino-aprendizagem de cada uma das disciplinas, visando sua organização pedagógico-didática, em correspondência com os níveis de ensino a atender e as características individuais e socioculturais dos alunos.

\section{Conclusão}

Neste texto buscou-se explicar a inseparabilidade entre conhecimento pedagógico e conhecimento disciplinar, conhecimento do conteúdo e conhecimento pedagógico-didático do conteúdo, didática 
e didáticas específicas. A lógica da argumentação desenvolvida aqui leva à conclusão de que um sistema de formação de professores precisa buscar uma unidade no processo formativo que assegure relações teóricas e práticas mais sólidas entre a didática e a epistemologia das ciências, rompendo com a separação e o paralelismo entre conhecimentos disciplinares e conhecimentos pedagógico-didáticos. Defende-se que os currículos de formação profissional, em todos os níveis do ensino, precisam assegurar que os futuros professores estejam preparados para analisar uma disciplina científica em seus aspectos históricos e epistemológicos; que tenham domínio da área pedagógica em temas ligados ao processo ensino-aprendizagem, ao currículo, às relações professor-aluno e dos alunos entre si, aos métodos e procedimentos didáticos, incluindo o uso da tecnologia educacional; que assumam seu papel de educadores na formação da personalidade dos alunos e que incorporem na prática docente a dimensão política enquanto cidadãos e formadores de cidadãos e profissionais.

Recebido em 31 de março de 2014 Aprovado em 29 de setembro de 2014

\section{Notas}

1 Neste texto, a expressão conhecimento pedagógico inclui necessariamente o conhecimento didático.

2 Esta expressão tem o mesmo significado de ensino desenvolvimental, tal como empregada por V. Davydov. O termo desenvolvimental corresponde à tradução da expressão em inglês developmental teaching e em espanhol enseñanza desarrollante, ambas traduções do russo. As expressões ensino desenvolvimental, didática desenvolvimental e didática para o desenvolvimento humano serão utilizadas aqui indistintamente.

3 Segundo Prestes, a unidade entre ensino e aprendizagem está expressa na palavra russa obutchenie, cuja tradução literal é instrução (Prestes, 2010, p. 188). Diferentemente do significado mais estreito de mera transmissão de conhecimento, com conotação pejorativa, a palavra se refere na língua russa ao processo simultâneo de instrução, ensino, estudo, aprendizagem, ou seja, ao processo ensino-aprendizagem. A instrução, assim, é a forma de organização do processo de apropriação, na qual estão implicados o ensino (o que o professor faz) e a aprendizagem (o que o aluno faz), ou seja, o ensinar por meio da atuação de outra pessoa no processo de aprendizagem.

\section{Referências}

ANASTASIOU, Léa das Graças Camargos; ALVES, Leonir Pessate (Org.). Processos de Ensinagem na Universidade. Joinville: Univille, 2006.

ANDRÉ, Marli Eliza Dalmazo Afonso de. A Produção Acadêmica sobre Formação Docente: um estudo comparativo das dissertações e teses dos anos 1990 e 2000. Revista Brasileira de Pesquisa sobre Formação de Professores, Autêntica, v. 1, n. 1, ago./dez. 2009.

ANDRÉ, Marli Eliza Dalmazo Afonso de. Tendências no Ensino de Didática no Brasil. In: PIMENTA, Selma Garrido (Org.). Didática e Formação de Professo- 
Formação de Professores e Didática para Desenvolvimento Humano

res: percursos e perspectivas no Brasil e em Portugal. São Paulo: Cortez, 1997. P. 215-230.

ARIZA, Rafael Porlán; TOSCANO, José Martin. El Saber Práctico de los Profesores Especialistas: aportaciones desde las didácticas específicas. In: MOROSINI, Marília Costa (Org.). Professor do Ensino Superior: identidade, docência e formação. Brasília: Plano Editora, 2001. P. 61-75.

CANDAU, Vera Maria Ferrão. Da Didática Fundamental ao Fundamental da Didática. In: ANDRÉ, Eliza Dalmazo Afonso; OLIVEIRA, Maria Rita Neto Sales de (Org.). Alternativas no Ensino de Didática. Campinas: Papirus, 2003. P. 71-95.

CANDAU, Vera Maria Ferrão. Diferenças Culturais, Cotidiano Escolar e Práticas Pedagógicas. Currículo sem Fronteiras, Lisboa; Porto Alegre, v. 11, n. 2, p. 240 255, jul./dez. 2011.

CANDAU, Vera Maria Ferrão (Org.). Didática Crítica Intercultural: aproximações. Petrópolis: Vozes, 2012.

CHAIKLIN, Seth. Developmental Teaching in Upper-Secundary School. In: HEDEGAARD, Mariane; LOMPSCHER, Joachim (Ed.). Learning Activity and Development. Arthus (Dinamarca): Aarthus University Press, 1999. P. 139-166.

CHEVALLARD, Yves. La Transposición Didáctica: del saber sabio al saber enseñado. Buenos Aires: Aique, 1991. P. 7-138.

CONTRERAS, José. A Autonomia de Professores. São Paulo: Cortez, 2002.

CORNU, Laurence; VERGNIOUX, Alain. La Didactique en Questions. Paris: Hachette/Centre National de Documentation Pédagogique, 1992.

DAMIS, Olga Teixeira. Formação do Profissional de Educação no Brasil: uma perspectiva de análise. In: VEIGA, Ilma Passos Alencastro; AMARAL, Ana Lucia (Org.). Formação de Professores: políticas e debates. Campinas: Papirus, 2002. P. 97-130.

DAVYDOV, Vasily; MÁRKOVA, Anastasia. La Concepción de la Actividad de Estudio de los Escolares. In: SHUARE, Marta (Org.). La Psicología Evolutiva y Pedagógica en la URSS: Antología. Moscú: Editorial Progreso, 1987. P. 316-337.

DAVYDOV, Vasily. La Enseñanza Escolar y el Desarrollo Psíquico: investigación psicológica teórica e experimental. Moscú: Editorial Progreso, 1988.

DEVELAY, Michel. Pour une Épistémologie des Savoirs Scolaires. Pédagogie Colégiale, Montreal, v. 7, n. 1, p. 35-40, out. 1993.

FRANCO, María Amélia Santoro. Didática e Pedagogia: da teoria do ensino à teoria da formação. In: FRANCO, Maria Amélia Santoro; PIMENTA, Selma Garrido. Didática: embates contemporâneos. São Paulo: Loyola, 2010. P. 75-100.

FRANCO, Maria Amélia Santoro. Pedagogia e Prática Docente. São Paulo: Cortez, 2012.

GATTI, Bernadete Angelina; NUNES, Muniz Rossa (Org.). Formação de Professores para o Ensino Fundamental: estudo de currículos das licenciaturas em pedagogia, língua portuguesa, matemática e ciências biológicas. São Paulo: Fundação Carlos Chagas/DPE, 2009.

GATTI, Bernadete Angelina; BARRETTO, Elba Siqueira de Sá; ANDRÉ, Marli Eliza Dalmazo Afonso de. Políticas Docentes no Brasil: um estado da arte. Brasília: MEC/UNESCO, 2011.

GATTI, Bernadete Angelina. Formação de Professores no Brasil: características e problemas. Educação e Sociedade, Campinas, v. 31, n. 113, p. 1355-1379, out./ dez. 2010.

648 Educação \& Realidade, Porto Alegre, v. 40, n. 2, p. 629-650, abr./jun. 2015 
GATTI, Bernadete Angelina. Políticas e Práticas de Formação Inicial de Professores: perspectivas no Brasil. In: LEITE, Yoshie Ussami Ferrari et al. (Org.). Políticas de Formação Inicial e Contínua de Professores. Araraquara: Junqueira e Marin Editores, 2012. P. 34-48.

GAUTHIER, Clermont et al. Por uma Teoria da Pedagogia: pesquisas contemporâneas sobre o saber docente. Ijuí: Editora Unijuí, 1998.

LIBÂNEO, José Carlos. Didática e Epistemologia: para além do debate entre a didática e as didáticas específicas. In: VEIGA, Ilma Passos Alencastro; D’ÁVILA, Cristina (Org.). Profissão Docente: novos sentidos, novas perspectivas. Campinas: Papirus, 2008. P. 59-88.

LIBÂNEO, José Carlos. Integração entre Didática e Epistemologia das Disciplinas: uma via para a renovação dos conteúdos da didática. In: DALBEN, Angela et al. (Org.). Convergências e Tensões no Campo da Formação e do Trabalho Docente: didática, formação de professores, trabalho docente. Belo Horizonte: Autêntica, 2010a. P. 81-104.

LIBÂNEO, José Carlos. O Ensino da Didática, das Metodologias Específicas e dos Conteúdos Específicos do Ensino Fundamental nos Currículos dos Cursos de Pedagogia. Revista Brasileira de Estudos Pedagógicos, Brasília, v. 91, n. 229, p. 562-583, set./dez. 2010b.

LIBÂNEO, José Carlos. O Campo Teórico e Profissional da Didática Hoje: entre Ítaca e o canto das sereias. In: FRANCO, Maria Amélia Santoro; PIMENTA, Selma Garrido (Org.). Didática: embates contemporâneos. São Paulo: Loyola, 2011. P. 43-74.

LIBÂNEO, José Carlos. O Dualismo Perverso da Escola Pública Brasileira: escola do conhecimento para os ricos, escola do acolhimento social para os pobres. Educação e Pesquisa, São Paulo, v. 38, n. 1, p. 13-28, mar. 2012.

LIBÂNEO, José Carlos. Licenciatura em Pedagogia: a ausência dos conteúdos específicos do ensino fundamental. In: GATTI, Bernadete Angelina et al. (Org.). Por uma Política Nacional de Formação de Professores. São Paulo: UNESP, 2013. P. 73-94.

LIBÂNEO, José Carlos. Didática e Docência: formação e trabalho de professores da educação básica. In: CRUZ, Giseli Barreto da et al. (Org.). Ensino de Didática: entre recorrentes e urgentes questões. Rio de Janeiro: Editora Quartet, 2014. P. 77-110.

LIBÂNEO, José Carlos; ALVES, Nilda (Org.). Temas da Pedagogia: diálogos entre didática e currículo. São Paulo: Cortez, 2012.

MASETTO, Marcos Tarcísio (Org.). Docência na Universidade. Campinas: Papirus, 2000.

MEIRIEU, Philippe. Aprender... Sim, mas Como? ArtMed: Porto Alegre, 1998.

NÓVOA, Antonio (Coord.). Os Professores e sua Formação. Lisboa: Publicações Dom Quixote, 1992.

NÓVOA, Antonio. Professores: imagens do futuro presente. Lisboa: Educa, 2009. OLIVEIRA, Maria Rita Neto Sales. A Reconstrução da Didática: elementos teórico-metodológicos. Campinas: Papirus, 1992.

OLIVEIRA, Maria Rita Neto Sales; ANDRÉ, Marli Eliza Dalmazo Afonso de. A Prática do Ensino de Didática no Brasil: introduzindo a temática. In: ANDRÉ, Marli Eliza Dalmazo Afonso de; OLIVEIRA, Maria Rita Neto Sales (Org.). Alternativas no Ensino de Didática. 12. ed. Campinas: Papirus, 2003. P. 7-18.

OLIVEIRA, Maria Rita Neto Sales; PACHECO, José Augusto (Org.). Currículo, Didática e Formação de Professores. Campinas: Papirus, 2013.

Educação \& Realidade, Porto Alegre, v. 40, n. 2, p. 629-650, abr./jun. 2015. 
Formação de Professores e Didática para Desenvolvimento Humano

PERRENOUD, Philippe. Práticas Pedagógicas, Profissão Docente e Formação: perspectivas sociológicas. Lisboa: Publicações Dom Quixote, 1993.

PIMENTA, Selma Garrido (Org.). Didática e Formação de Professores: percursos e perspectivas no Brasil e em Portugal. São Paulo: Cortez, 1997.

PIMENTA, Selma Garrido. Professor Reflexivo: construindo uma crítica. In: PIMENTA, Selma Garrido; GHEDIN, Evandro (Org.). Professor Reflexivo no Brasil: gênese e crítica de um conceito. São Paulo, Cortez: 2002. P. 17-52.

PIMENTA, Selma Garrido. Epistemologia da Prática: resignificando a didática. In: FRANCO, Maria Amélia Santoro; PIMENTA, Selma Garrido. Didática: embates contemporâneos. São Paulo: Loyola, 2010. P. 15-41.

PRESTES, Zoia Ribeiro. Quando não é Quase a Mesma Coisa: traduções de Lev Semionovitch Vigotski no Brasil. Campinas: Autores Associados, 2012.

SACRISTÁN, José Gimeno. Tendências Investigativas na Formação de Professores. In: PIMENTA, Selma Garrido; GHEDIN, Evandro (Org.). Professor Reflexivo no Brasil: gênese e crítica de um conceito. São Paulo: Cortez Editora, 2002. P. 81-88.

SAVIANI, Dermeval. Formação de Professores: aspectos históricos e teóricos do problema no contexto brasileiro. Revista Brasileira de Educação, Rio de Janeiro, v. 14, n. 40, p. 142-155, jan./abr. 2009.

SHULMAN, Lee. Conocimiento y Enseñanza: fundamentos de la nueva reforma. Profesorado. Revista de Currículum y Formación del Profesorado, Granada, v. 9, n. 2, p. 1-30, 2005. Disponível em: <http://www.ugr.es/ recfpro/Rev92. html>. Acesso em: 15 abr. 2012.

TARDIF, Maurice. Saberes Docentes e Formação Profissional. Petrópolis: Vozes, 2002.

VEIGA, Ilma Passos Alencastro. A Prática Pedagógica do Professor de Didática. 10. ed. Campinas: Papirus, 1999a.

VEIGA, Ilma Passos Alencastro (Org.). Repensando a Didática. 25. ed. Campinas: Papirus, 1999b.

VEIGA, Ilma Passos Alencastro. Docência como Atividade Profissional. In: VEIGA, Ilma Passos Alencastro (Org.). Profissão Docente: novos sentidos, novas perspectivas. 2. ed. Campinas: Papirus, 2010.

VEIGA, Ilma Passos Alencastro. Docência na Educação Superior e as Didáticas Especiais: campos em construção. Educação (UFSM), Santa Maria, v. 36, n. 3, set./dez. 2011

VYGOTSKY, Lev. Pensamiento y Habla. Tradução de Alejandro Ariel González. Buenos Aires: Colihue, 2007.

VYGOTSKY, Lev. A Formação Social da Mente. São Paulo: Martins Fontes, 1984.

José Carlos Libâneo é doutor em Filosofia e História da Educação pela PUC São Paulo. Professor Titular aposentado da UFG. Professor Titular da PUC Goiás, atuando no Programa de Pós-Graduação em Educação. Pesquisa e escreve sobre temas de teoria da educação, didática, organização escolar, políticas para a escola e ministra conferências em congressos e encontros realizados no país e no exterior.

E-mail: libaneojc@uol.com.br

650 Educação \& Realidade, Porto Alegre, v. 40, n. 2, p. 629-650, abr./jun. 2015. 